\title{
Archaeobotanical and GIS-based Approaches to Prehistoric Agriculture in the Upper Ying Valley, Henan, China
}

\author{
Hai Zhang ${ }^{1}$, Andrew Bevan ${ }^{2}$, Dorian Fuller ${ }^{2}$ and Yanming Fang ${ }^{3}$ \\ Postprint of a 2010 paper in Journal of Archaeological Science 37.7: 1480-1489 \\ (doi: 10.1016/j.jas.2010.01.008).
}

\begin{abstract}
Archaeobotanical survey has sampled a series of late Neolithic to early Bronze Age settlements in the upper Ying valley (part of the central plain of China) and provided useful data for understanding prehistoric arable ecology and farming during a period of increasing local social complexity. A combination of the modelling functions offered by Geographic Information Systems (GIS) and the data reduction possibilities offered by Principal Component Analysis (PCA) allow us to explore the relationships between local arable ecology, crop-processing strategies and the natural environment. The results suggest that differences in the natural environment around each site are a good explanation for varying patterns of wild food collection, but in contrast, social and cultural factors seem to be much better at explaining variation in farming practice and crop-processing at different sites.
\end{abstract}

\section{Keywords}

archaeobotany, crop processing, millet, rice, Principle Component Analysis, Mantel Matrices

\section{Introduction}

Over the last few years, archaeobotany has provided an increasingly important perspective on the rise of early complex societies in China (e.g. Zhao 2005, 2006). This methodological emphasis both reflects and has encouraged the development of a wider body of theory about the development of prehistoric agriculture in the central plain of China (e.g. Jin and Luan 2006; Lee and Bestel 2007). While most of this work has been focused at the intra-site scale, nevertheless, wider regional patterns of crop use and population change have also attracted attention, primarily through the collection of archaeological survey datasets (Qiao 2007; Lee et al. 2007; Fuller and Zhang 2007). What has mostly been missing up to present however, has been a systematic, quantitative attempt to integrate site-based archaeobotany with a broader landscape-scale analysis.

This paper seeks to fill this gap: it draws its data from an archaeobotanical survey project along the upper Ying valley, in China's central plain, that was designed to explore the relationship between changing agricultural strategies and the emergence of more complex society over the crucial period from the late Neolithic to early Bronze Age (ca.4000-1500 BC). Despite the project only being able to collect samples

Corresponding Author: School of Archaeology and Museology, Peking University, Beijing 100871, China

UCL Institute of Archaeology, 31-34 Gordon Square, London WC1H 0PY, United Kingdom

Henan Provincial Institute of Cultural Relics and Archaeology, Zhengzhou 450000, China 
from a relatively small number of sites, the results have revealed interesting and recurrent trends in crop processing and subsistence strategies in the region (Fuller and Zhang 2007). Moreover, this preliminary analysis has suggested that some of the variability in observed archaeobotanical patterns might be explained by their spatial correlation with particular environmental variables, or their temporal correlation with particular cultural changes (Zhang 2007: 770-773). This paper therefore considers these correlations more formally, taking advantage of the exploratory and confirmatory potential offered both by modern Geographic Information Systems (GIS) and multivariate statistics.

The upper Ying valley is an alluvial basin in Henan province, bordered by the Luoyang basin to the northwest, within China's central plain (figure 1a). It is in this region that China's earliest state-level society developed in the early 19th century BC (Lee 2002; Liu and Chen 2003). Bounded by the Songshan mountains to the north and the Jishan mountains to the south, the Ying river flows west to east, gradually gathering new branch streams from the adjacent mountains. Most prehistoric sites are found at the locations where these branches converge (figure 1b) and, from the 1950s onwards, this was one of the first areas where Chinese archaeologists looked for the origins of Chinese civilization (Xu 1959). Since then, no less than five archaeological survey projects have been carried out in this region and nearly 40 sites dating from late Neolithic to early Bronze Age have been discovered (LAT 1961; HPICR and CCRYC 1991; An 1997; HPICRA et al. 1998; Zhang 2007).

The local chronology in this region is based on both ceramic typology and radiocarbon dating and, in combination, these suggest three broad archaeological divisions (Zhang 2007: 760-763): a late Neolithic 'Yangshao' phase (ca.4000-2500 BC), a transitional 'Longshan' phase (ca.2500-1800 BC) and an early Bronze Age 'Erlitou' phase (ca.1800-1600 BC). Although more precise sub-periods can sometimes be distinguished, the relatively small number of individual sites in the area does not usually facilitate archaeological interpretation at the level of these more detailed time spans. Previous work has also distinguished two different groups of settlements in this region, each with distinct cultural traditions and different levels of social complexity (Zhang 2007: 672-684). For our purposes here however, we focus on just one group of settlements, in the upper Ying valley, comprising 18 individual locations, with evidence from one or more of the three main archaeological periods.

\section{Research Context}

Previous research has identified the basic subsistence crops used in this region during the late Neolithic to early Bronze Age (Fuller and Zhang 2007). Millet (Setaria italica and Panicum miliaceum) was the dominant crop throughout, with Setaria italica the dominant species. Rice (Oryza sativa) was present at almost all sites and in most periods, but it is only a minority component of the total, archaeologically-recovered, cereal assemblage and seems to have been relatively rare. The soybean (Glycine max/soja) probably was collected as a wild species although a domestication process 
by Longshan times is possible. Wheat (Triticum $s p$.) first appeared in the area during the early Bronze Age and must have been introduced to China from the West (Zohary and Hopf 2000: 57-58), but there is no clear evidence that this introduction significantly changed the profile of local food consumption at this stage. Overall therefore, the data offers a relatively consistent picture of crop use over time and between the settlements of the valley, but a picture that becomes more varied when, instead, we consider potential diversity in crop harvesting and processing between individual sites.

The sequence of operations involved in these tasks allows for substantial variation in practice, as well as opportunities for both innovation and information-sharing between people or communities. Harvesting is addressed again below, but it is worth noting here that an important recent agenda in archaeobotany has been the need to improve our understanding of the different strategies involved in crop-processing (e.g. Van der Veen and Jones 2006; Fuller ans Stevens 2009). Increasing attention has also been paid by Chinese archaeologists to this issue over the last few years, both in the discussion of carbonized plant remains (Fuller and Zhang 2007) and phytolith assemblages (Jin et al. 2007). In theory, all of the different stages that crops go through, from the field to the cooking pot, are of potential interest to archaeobotanists, including harvesting, drying, threshing, winnowing, storage, pounding and sieving. At each stage, there may be corresponding waste left at an archaeological site suggesting, at first glance, a huge number of different, contingent and context-specific explanations for a given set of plant remains. However, ethnoarchaeological research suggests that what is, in fact, most regularly observed in the archaeological record of settlement sites is typically the waste from the routine, everyday work involved in transforming the crop from its state-in-storage to something ready for cooking (Stevens 2003). Accidentally or deliberately burnt for some reason, the charred remains from this kind of routine crop-processing find their way into everyday rubbish and the fills of other kinds of archaeological feature.

A key contribution that this proposed model of routine crop-processing makes is to suggest that the nature of the archaeological features themselves will often have limited bearing on the patterns of routine crop-processing remains that are present, as long as the deposits in these features show signs of including everyday rubbish. More practically, it also implies that we can hope to address questions of local farming practice by considering the overall content of archaeological plant assemblages, rather than only concentrating on the minutiae of their separate archaeological contexts (e.g. Harvey and Fuller 2005: 741; Fuller and Stevens 2009). This model therefore offers a crucial underpinning for archaeobotanical survey, indicating that we might reasonably investigate regional-scale variation in agricultural activities via archaeobotancial samples that have been collected from different sites and different contexts. Such a methodological assumption is particularly relevant in the central plain of China, where most sites have been in continuous occupation for hundreds of years and the plant remains within each site had been redeposited, moved and mixed repeatedly. 
This methodological emphasis on investigating routine crop-processing patterns can also provide insight into the varying ways in which labour might be mobilised for farming activities. For example, if reasonably abundant sources of human and animal labour are available for crop-processing in the stages prior to crop storage, then this reduces the need for such processing later on, making the subsequent, everyday use of these stored crops far more convenient, because they now include comparatively less chaff, spikelet bases, straw and weeds (Fuller and Stevens 2009). The degree of pre-storage labour input will often therefore have an on-site archaeological signature that we explore further below. In any case, the preliminary study of the archaeobotanical survey results (Fuller and Zhang 2007) revealed some recurrent crop-processing patterns in the upper Ying valley, but further analysis is still needed. Many different factors, both social and natural, might exert an influence on farming practices, how communities stored their food, and/or the time and labour spent on different stages of crop-processing. In the discussion below, we therefore deploy a range of multivariate statistics and GIS-led methods to explore these potential causal factors further. More precisely, we will consider the possible role of geographical proximity and social connectedness among prehistoric sites in this area, possible changes in practice over time, and also variation in the natural environment around each site. The following section describes the creation and integration of these various analytical variables in greater detail.

\section{Dataset Preparation}

\subsection{Archaeobotanical Data}

The collection of archaeobotanical samples suitable for studying the complexity of arable ecology and agricultural activities was a core objective of recent regional survey of the upper Ying valley, but despite this targeted effort, the overall number of available samples is limited. Of the 20 late Neolithic to early Bronze Age sites recorded by previous surveys in this region, only 18 remain sufficiently well-preserved to allow re-exploration, and, of these, only 9 have exposed archaeological deposits from which sufficiently large soil samples for flotation could be obtained from clean contexts. Table 1 lists these sites and offers a summary of the samples taken from them (see figure $1 \mathrm{~b}$ for their locations). In general, multiple samples were taken from each site and, with one possible exception (the Erlitou period site of Shidao), these exhibit reassuring uniformity in their archaeobotanical results, prompting us, for our purposes here, to work with a single generalized archaeobotanical pattern for each site. Below we draw upon the raw analysis of these samples (details in Fuller, et al. n.d.) to generate a range of indices relevant to two broad aspects of the agricultural economy in this region, that we can loosely term arable ecology and crop processing.

\subsubsection{Arable Ecology}

This is a broad term that is used here to refer to the general biological environment in which agricultural activities take place, particularly with respect to the overall balance 
of weed, wild fruit and crop types. For each site, six variables have been calculated from the original archaeobotanical data: the ratios of (i) rice to millet and (ii) Setaria to Panicum, and the percentages of (iii) wetland weed species, (iv) dryland weed species, (v) soybeans and (vi) wild fruits (table 2).

The first two of these measures can potentially be used as indicators of crop choice. Since the cultivation of rice requires more sophisticated drainage systems than millet, and since rice also seems to have been less common overall than millet in the local economy (Lee et al. 2007: 1092; Lee and Bestel 2007: 57), local variations in the ratio of rice to millet may reflect local community decisions about crop priorities and variations in the sophistication of local agricultural techniques. Turning to the cultivation of millet in particular, the ratio of Setaria to Panicum may provide a useful indicator of the varying scale of local agricultural production. For example, later Chinese historical records (e.g. Qimin Yaoshu Vol.2 Shuji) indicate that Panicum was often used as a pioneer species to settle new millet planting areas and a large percentage of Panicum within the millet assemblage might therefore reflect the expansion of agricultural production into new fields. The second two measures can perhaps be used for subtler characterisation of the local environment for agriculture. For example, most of the weed species discovered in the survey are those that infest fields-in-crop and some of them reflect distinctive adaptations to wetter or drier land environments. The last two percentages offer a possible window onto the importance of wild food collection in the local ecology. While soybeans are present in considerable quantities in most of the archaeobotanical assemblages considered here, morphological analysis suggests that most of them are wild species and should therefore be viewed as one of the most important collected foods.

In order both to explore the interdependence of these six variables and to simplify subsequent comparison, we used Principle Component Analysis (PCA) to reduce them to three main factors (table 3, hereafter referred to as Arable Ecology Factors 1-3: or AEF1-AEF3), with a good level of extraction and accounting for $85 \%$ of the overall variance. The rotated components ${ }^{4}$ show that the two original wild food collection indices (for soybeans and wild fruits) are strongly correlated and best explained by AEF1. Similarly, the original wetland and dryland weed variables are best simplified by AEF2, and the original ratios of rice to millet and Setaria to Panicum as AEF3.

\subsubsection{Crop Processing}

Crop-processing here refers to harvesting methods and post-harvest crop-processing activities. Harvesting is the first stage of crop-processing and the main source of variation here relates to the height at which the crop is harvested, for which we can make a rough distinction between (i) uprooting, (ii) reaping low on straw and (iii)

\footnotetext{
There is debate amongst archaeologists and others about whether it is appropriate to use a rotation of the main PCA factor axes or not (e.g. Shennan 1997: 301-303). However, for our purposes here, the rotation produces more balanced explanatory percentages between the three extracted factors so we have proceeded with it.
} 
reaping high on straw. Ethnoarchaeological research indicates a range of factors that might encourage the harvesting of crops at a particular height, including the nature of the crop, its broader ecology, the conditions of its planting, local or adopted cultural tradition etc., (Hillman 1984: 117-120). These different influences may sometimes be discerned from the analysis of weed species vs. plant height: more precisely, if we assume that the weeds are harvested together with the crops, then uprooting and reaping low on straw might be represented in a weed pattern with more low-height stalks or prostrate species (see Li 1998 for Chinese weed heights). In contrast, reaping high on straw is likely to pick up more tall-standing weed species. Here, we calculate two measures for each species and then take the average: the mean of maximum weed height and the mean of minimum weed height (table 4).

For understanding variation in routine crop processing, two ratios may be suggested for millet archaeobotany as useful indicators (Fuller and Zhang 2007; cf. Harvey and Fuller 2005): the ratio of grains to weeds and the ratio of hulled \& immature to unhulled \& mature grains (table 4). At different stages of crop processing, these two ratios can change dramatically. For example, higher proportions of hulled and immature grains are expected in threshing products than in dehusking, winnowing and sieving processes. The latter should also reduce the proportions of weed seeds. While the actual processes responsible for variation in these ratios are known to be very complex, i.e. immature proportions may be affected by quality of grain-filling or harvest timing, while charring condition may affect levels of husk preservation. The grain to weed ratio may also be influenced by time spent on eliminating the weed from crops regardless of field management or other crop harvesting practices. Nevertheless, we expect these patterns to generally reflect patterns created by crop-processing.

\subsection{Geospatial Data}

In order to make sense of these site-specific archaeobotanical variables, we need to be able to see how strongly they correlate (or not) with neighbouring sites and/or with a model of the varying local environment around each site. Fortunately, modern remote sensing and Geographic Information Systems (GIS) allow us to exploit near-exhaustive environmental coverages (albeit at particular spatial resolutions) and to examine spatial relationships with ever increasing efficiency in terms of time and cost. Below, we outline the methods we have deployed for this purpose.

\subsubsection{Primary Coverages}

Our primary topographic coverage is a $30 \mathrm{~m}$ digital elevation model (DEM) of the upper Ying valley that was extracted from the band 3 pair of an ASTER satellite image (e.g. Abrams 2002) and slightly adjusted, in both the horizontal and vertical plane, on the basis of known ground control points (figure 2a). Various secondary datasets were produced from the DEM, but three additional primary coverages consist of a geology map, an annual precipitation map and soil map (figures $2 b-d$ ). The geological data was initially digitised from a 1:500,000 scale paper map (HPBGM 
1989), but was then adjusted for greater accuracy by checking the major unit borders on a composite of the ASTER short-wave infared bands (the latter dataset being commonly used for geological prospection). In particular, the accurate mapping of the first and second-stage, Pleistocene river terraces is crucial as this is where most of the archaeological sites are located. The precipitation and soil maps were digitised from coarser 1:1,000,000 scale maps (CHRRMWR and NIGLCAS 1999).

\subsubsection{Cost Surfaces and Agricultural Catchments}

One of the purported strengths of GIS for archaeologists has been its ability to model the cost of travel across a landscape, and thereby to explore both possible routes of past movement and to model possible economic or political territories. In fact, there have been a host of methodological failings associated with the way such cost surface models (as they are known) have been constructed. These have led in the past to some very unreliable results (for a recent discussion and further references, see Bevan in press), but more recent software implementations, such as the r.walk module in GRASS GIS (Fontenari et al. 2005) are much better-designed in this respect and are able to model the combined effects of anisotropic influences on travel time such as steepness of slope, as well as isotropic costs such as variable land cover. Here, we calculated individual cost surfaces from each site, based on the impact of variable terrain and added an extra 20-30 minutes for river crossings (depending on stream width). An example of such a cost surface is shown in figure $3 \mathrm{a}$.

These cost surfaces also allow us to propose which parts of the surrounding landscape should be allocated to which contemporary site, based on shortest travel time. There are of course many other factors affecting the organization of agricultural holdings (at this village scale), but travel time is often an important factor and several studies have emphasised that a one-hour round-trip to the fields and back represents a key, cross-culturally relevant threshold (e.g. Chisholm 1968: 45-49; Zahavi 1979: 61-103; Bevan et al. 2003: 230). We therefore defined possible catchments for the upper Ying sites (separately for each phase) by first allocating each part of the landscape (i.e. each cell in our raster datasets) to the nearest site in terms of travel time, and then cropping these allocations to a maximum travel time of one hour (e.g. figure $3 b$ ).

\subsubsection{Geographical Proximity}

Here we consider two simple, geographical measures of the spatial relatedness of individual prehistoric sites: distance and adjacency. The first of these refers to Euclidean 'as the crow flies' distances between sites, while the second is coded as a topological relationship between site catchments: either partially overlapping ( 0 ; primarily relevant for non-contemporary site catchments), adjacent (1) or not adjacent (2). In all cases, we have decided to calculate these measurements between all pairs of sites regardless of their chronological phase, because, in contrast to the more socially-focused network indices considered below, here we wanted to consider geographical proximity as a plausible causal factor behind both the spatial diffusion of farming techniques over time and the cultural inheritance of such techniques from 
adjacent ancestral sites. This is also the reason why we prefer simple Euclidean distances, assuming that more topographically-sensitive walking distance would make less sense for non-contemporary sites.

\subsubsection{Social Networks}

Beyond these generic, chronology-free measures of proximity however, we are also interested in the complementary or contrasting impact of more highly social relationships between contemporary sites in the region. Two variables based on network analysis have therefore been included here: connectivity and accessibility. For both indices, we first create a topographically-sensitive network of linkages between contemporary sites, combining both terrestrial and riverine travel times. In the absence of any detailed knowledge of actual trackways in this period, the former are calculated via the cost surfaces produced for the site catchments above, and represent the shortest (anisotropic) walking time from one site to another overland. The latter assumes travel by canoe along the local waterways ${ }^{5}$ and, for simplicity, averages out the directional and seasonal complexity that this would have involved, assuming instead, an even isotropic speed of ca.10 km per hour along the river system (e.g. Heyen 1972:72; Finney 1977). These terrestrial and riverine linkages builds a network among contemporary sites that allows as to consider the place of any individual site in its wider probable social context (figure 4a-c). Here we use two common network indices: a connectivity index evaluates the degree to which a site is well- or poorly-connected relative to others, while an accessibility index suggests how easily a site can be reached from any point in the network (for further details, see Conolly and Lake 2006: 234-252).

\subsubsection{Sites and Their Local Environment}

In order to investigate whether differences in the environment around each community might explain some of the variation in their farming practices, we also summarised a range of variables for each site's proposed catchment: (i) slope, (ii) exposure to prevailing winds, (iii) surface water flow, (iv) amount of river terrace, (v) precipitation and (vi) amount of different soil types.

The mean of logged slope was used for each catchment to avoid any problems of statistical summary that might arise from taking the mean of raw slope values, particularly in light of the fact that the latter are often lognormally-distributed (e.g. Speight 1971). The dominant winds in the region are from the northwest in the winter and from the east in the spring and summer (Editors for Dengfeng City Annuals 2008: 85 ), and exposure to these was measured for each grid cell based on the degree to which its aspect deviated from these prevailing directions. Surface water flow was measured as mean logged flow accumulation, again to avoid problems associated with

\footnotetext{
All of the sites in this study are located next to rivers and later historical documents also emphasize the importance of river systems for transport and political control in the central plain of China. The most famous record in this regard is the Yugong (regarded as one of the earliest Chinese historical documents) which suggests that the Great Yu, believed as the first king of the central kingdom of China, was the first to use the river systems to unify all nine states of China and also draw upon them for supplies (Yugong Jiuzhou).
} 
a typically skewed distribution. The total area of river terrace in a catchment was used here as a very rough proxy measure for prime arable land, in light of the fact that the location of prehistoric sites is significantly-correlated with river terrace zones (K-S one-sample test, $\mathrm{p}=0.005$ ) and these areas are known by modern farmers to offer many advantages in terms of fresh water supply, field management and soil quality. Precipitation was calculated as the mean value per catchment. The local soils of the region can be lumped into four broad categories (cinnamon, chao, purplish and skeletal soils), based on the mineral components, $\mathrm{pH}$ value, granulometry and physical structure (CHRRMWR and NIGLCAS 1999). The total amount of each soil type was calculated and included as separate values in the principal component analysis described below.

The summary values for each site catchment were then subject to PCA in order both to explore patterns of interaction between the variables and to reduce their complexity down to something more manageable. The results in table 5 suggest that the first four PCA factors (hereafter referred to as Natural Environment Factors 1-4: or NEF1-NEF4) account for nearly $90 \%$ of the variance and all but one of the original variables attains more than $80 \%$ extraction. NEF1 broadly reflects the association between increased water flow, amounts of river terrace, amounts of chao soil and lessening exposure to the dominant spring/summer wind from the east. NEF2 can be used to characterise the association between steepening slope, increasing amounts of cinnamon soil and decreasing amounts of chao soil. NEF3 broadly reflects the link between more annual rainfall, increasing amounts of purplish soil and decreasing amounts of skeletal soil. Finally, NEF4 mainly explains patterns associated with increasing exposure to the dominant winter wind from the northwest.

\section{Data Analysis}

We now turn to ways in which we can make use of the above datasets to understand the complex relationships that potentially exist between a particular prehistoric community's farming practices and its wider social and natural environment. Such a research objective is fraught with difficulties: some of these difficulties relate, of course, to the small number of sampled sites, as well as to problems of archaeobotanical taphonomy, GIS algorithms and multivariate data generalization. Further difficulties also relate to the problems associated with unpicking multivariate relationships in situations where pronounced patterns of spatial and temporal dependence and/or heterogeneity exist (as recent reviews in both ecology and archaeology have re-emphasised: Miller et al. 2007; Bevan and Conolly 2009). As the above should indicate however, we see many of these difficulties as surmountable, and with regard to the latter problems of spatio-temporal dependence, we have here taken care to: (i) reduce the spatial heterogeneity in our dataset by restricting the study to similar types of site in the upper Ying valley only (see above), (ii) incorporate explicit spatial and temporal factors in our analysis, and (iii) make use of Mantel matrices that work well with measures of spatio-temporal distance. Below our analysis proceeds in two steps, considering first a global regression of the above 
datasets, and then results from Mantel matrix tests.

\subsection{Linear Regression}

In this section, we use a linear regression to discuss possible relationships between the archaeobotanical data and GIS-based environmental data. One of the advantages of the PCA approach adopted above is that our new variables are now uncorrelated with one other, making it possible to proceed with a sequence of pair-wise regressions with greater confidence. To control for possible chronological variation, we have also divided the sites into two groups: Yangshao Period (ca.4000-2500BC) and Longshan to Erlitou Period (ca.2500-1600BC).

The results are presented in the table 6 . Those high correlation coefficients with low p-values suggest that AEF1 is correlated with NEF1 and, to a less significant extent, also with NEF3. This implies a linkage between variation in differences in wild food collection strategy and differences in the local environment around each site, including greater exposure to the spring/summer wind, greater local water flow, the presence of more river terrace land, greater rainfall and certain preferred soil types. However these correlations (between AEF1 and NEF1) lessen for the later Longshan-Erlitou sites, possibly due to an overall decrease in wild food collection in the late period or to the small number of analytical samples. AEF2 on the other hand is strongly correlated with NEF4 (but only at marginal levels of statistical significance for each phase with the present sample). This implies that the original variables recording percentages of wet and dryland weeds are possibly linked to patterns of exposure to the prevailing winter wind.

Two further bits of negative evidence are of possible interest. First, NEF2, which primarily reflects the variability of terrain slope and cinnamon soil has no clear correlation with any of the archaebotanical data, whether the latter relates to farming or collecting practice. Second, AEF3, which relates to variation in the ratios of different crops also does not however exhibit any clear correlations with diversity in a site's natural environment. In general therefore, these linear regression results demonstrate that diversity of natural environment around each site can often explain the diversity in collecting behaviors but does not really explain diversity in farming behaviours. Indeed, the possible association of weed species (that we assume to be infesting farmed plots) with areas more exposed to the dominant winter wind also implies a natural cause for this variation rather than a cultural one.

\subsection{Mantel Matrix Tests}

A Mantel matrix test can provide statistical confirmation of linear correlations within matrices that measure similarity or dissimilarity between pairs of observed phenomena (Mantel 1967). Here, our pairs of observations are archaeological sites of the same phase and we convert our factors measuring geographical distance, social connections, chronology, environmental diversity and farming practice into dissimilarity matrices. The chronological difference between each pair of sites was 
expressed as a binary relationship indicating whether the sites were contemporary (1) and or not (0). This binary relationship was preferred over a linear scale of temporal similarity, in light of preliminary work which had suggested non-linear, oscillating variation in the intensity of crop processing over time (Fuller and Zhang 2007: 928-931, 954-958).

However, prior to considering how (i) our archaeobotanical data might be explained by (ii) our spatial, temporal and environmental variables, we first address possible interdependent relationships within the second of these datasets (which now include both the uncorrelated NEF factors and the other variables for chronology, distance, social connectivity, etc.) via a partial mantel matrix test in which two matrices are considered with a third one controlled. The results are shown in table 7 and suggest significant positive correlations between NEF3, accessibility and adjacency. A Further partial mantel tests indicate that the correlation between adjacency and accessibility disappears when the NEF3 is controlled $(r=0.198)$ and the same is true for the NEF3 and adjacency variables with accessibility controlled $(\mathrm{r}=0.179)$. However the relationship between NEF3 and accessibility remains strong with $(\mathrm{r}=0.731)$ or without $(\mathrm{r}=0.794)$ control. We suggest that this relationship is partly driven by the fact that sites located near the centres of networks also have catchments with higher annual rainfalls, greater amounts of purplish soils and lesser skeletal soils. Of course geographical distance and adjacency are also strongly correlated but it remains useful to treat them separately in the following analysis.

Table 8 then shows results from mantel matrix or partial mantel matrix tests (the choice of which is informed by the presence or absence of correlations in table 7) considering the relationship between those archaeobotanical indices relevant to farming practice and the various possible explanatory variables. Reassuringly, these tests come to the same conclusion as the linear regression with respect to the complete lack of correlation between the environmental variables and farming strategies. On the other hand, they also indicate that variation in weed harvesting height is correlated with simple geographic distance, but even more strongly with catchment adjacency. Furthermore, for the crop processing variables, we can note that the ratio of hulled/immature to unhulled/mature grains is significantly correlated with chronological phase, and the ratio of grains to weeds with a site's degree of accessibility within the social network (but interestingly not its number of connections). In general, therefore the Mantel matrix test results confirm those from our previous linear regression and also indicate that variation in harvesting and crop processing strategies are probably better explained by social and cultural factors, rather than environmental ones.

\section{Discussion}

Both recent theoretical models and preliminary analysis of the upper Ying data broadly supports the assumption that we can compare site-specific archaeobotanical samples to try to understanding patterns of regional variation in agricultural practice. 
A series of commonly-used measures have therefore been produced that can plausibly be used as proxies for understand variation in harvesting practice, wild food collection and routine crop processing. In addition, we have made use of GIS to calculate various measures of inter-site proximity, to suggest possible site catchments and then to quantify aspects of the natural environment within each catchment. Thereafter, PCA allowed us to compress the complex results from the archaeobotanical study and the GIS-derived environmental variables into more analytically meaningful and intuitively manageable groups. Linear regression and Mantel matrices were then used as both exploratory and confirmatory methods for investigating how these different groups of variables co-vary and, ultimately, to suggest possible causal relationships.

On the one hand, the results suggest that differences in the natural environment around each site only really have a significant impact on patterns of soya and wild fruit collection, and have little to do with differences in farming practice between sites. On the other hand, social and cultural factors seem to be much better at explaining variation in farming practice at different sites. More precisely, similar habits with regard to harvesting height are typically shared by neighbours but not clearly related at any larger regional level. This conclusion deserves to be set back within its wider archaeological context. For example, study of the stone and shell remains from the Wangchenggang site suggest that there are two types of harvesting tool: a stone knife (that could be perforated or unperforated) and a sickle made of either stone or mussel shell. Li Yangsong has reconstructed the way these two tools were most likely used, on the basis of ethnographic comparison (School of Archaeology and Museology in Peking University 2002: 34), suggesting that the knives were held in hand to cut down cereal spikes from the tops of stems. In contrast, the stone or shell sickles had serrated edges and a bent shape that allowed them to be tied on the end of wooden sticks and used to cut crops from the bases of their stems (figure 5). So generally-speaking, the knife and sickle can be seen as two kinds of tools which were used to harvest crops at different heights. These suggestions have obvious relevance to our statistical findings here and, in future, might be taken further through greater attention to the tool repertoires at different sites in the upper Ying valley.

For patterns of routine crop-processing (as represented by proxy indicators such as the ratios or grain to weed or hulled/immature to unhulled/mature grains), it is intriguing that one of the social network variables provided the best explanation More interesting still, it is not the overall network structure or the number of connections that a site enjoyed that seems to have been important, but its accessibility within the local network. However, the details of the correlation here are important: the lower the accessibility index, the more easily a site could be reached from all others in the network, while the larger the grain to weed ratio and the smaller the hulled/immature to unhulled/mature ratio, the more labour and time was arguably devoted by the community to crop processing before storage. Hence, we actually have a negative correlation whereby the more accessible an individual site was within its immediate 
social network, the less time and effort it typically seems to have spent organising the extra labour necessary to process crops prior to storing them. This may suggest that agriculture was organized on a smaller scale in more focused units of production. More peripheral sites seem to have devoted more effort than more accessible ones, which may be a product of agricultural labour units, of larger households, extended social networks across the community. Overall this, and the previous results with respect to harvesting, might suggest the absence of much regional level organization to agriculture during this period. Habits were mainly consistent among immediate neighbours and the more accessible sites may have used their position for other cultural or political purposes but, if anything, these other purposes may have distracted, rather than encouraged, them from more intensive crop processing. What comes through the entire analysis is therefore the continuing local-scale of much farming activity, via the local household or semi-communal larger units. This household approach can be documented as having been the dominant mode of food production for many millennia of later Chinese history. Rice is, by contrast, one crop that some commentators have suggested was for elite consumption and might have been produced by more regional scales of labour organization (Lee et al. 2007: 57), but if so, we still need to find evidence for this in the upper Ying valley data.

Finally the importance of chronology remains a little difficult to decipher, not least because this study covers periods during which there is a notable increase in population. Expansion of population through founding new settlements, initially small, might have opened networks of communities in which an ad hoc family-focused approach was at first necessary and then later traditional. Declining soil fertility, including through expansion to more marginal lands, would probably also increase the number of immature seeds and add to the difficulty of husk-threshing.

In any case, such questions point clearly to the need for further research, and this paper has sought not only to promote such additional questioning but also to highlight the promise of archaeobotanical survey at the regional scale and emphasise the potential of interrogating the results via a combination GIS and multivariate statistics. 


\section{References}

Abrams, M. (2002). Aster Users Handbook, Pasadena: NASA Jet Propulsion Laboratory.

An, J. (1997). Yuxi yinghe shangyou zai tansuo Xia wenhua yicun zhongde zhongyao diwei (Significant positions for research of Xia culture in upper of Ying River Valley in west of Henan province). Kaogu Yu Wenwu 3: 54-60. (In Chinese).

Bevan, A. and Conolly, J. (2009). Modelling Spatial Heterogeneity and Nonstationarity in Artifact-Rich Landscapes', Journal of Archaeological Science 36.4.

Bevan, A., C. Frederick, and N. Krahtopoulou (2003). A digital Mediterranean countryside: GIS approaches to the spatial structure of the Post-Medieval landscape on Kythera (Greece). Archeologia e Calcolatori 14: 217-236.

Bevan, A. (in press). Computational models for understanding movement and territory. in: Mayoral, V. and S. Celestino (eds.) . Sistemas de Información Geográfica y Análisis Arquelógico del Territorio. V Simposio Internacional de Arqueología de Mérida, Anejos de Archivo Español de Arqueología

Chisholm, M. (1968) Rural Settlement and Land Use, London: Hutchinson.

Committee of Huaihe River Resources in Ministry of Water Resources (CHRRMWR), Nanjing Institute of Geology and Lake in China Academy of Science (NIGLCAS) (1999). Huaihe liuyu dituji (Atlas of Huaihe River). Beijing: Science Press. (In Chinese).

Conolly, J., M. Lake (2006). Geographical Information Systems in Archaeology. Cambridge: Cambridge University Press.

Editors for Dengfeng City Annuals (2008). Dengfeng City Annuals. Zhengzhou: Zhongzhou Ancient Book Press.

Finney, B. (1977). Voyaging Canoes and the Settlement of Polynesia. Science 196: 1277-1285.

Fontenari, S., S. Franceschetti, D. Sorrentino, F. Mussi, M. Pasolli, M. Napolitano, and R.Flor (2005). r.walk. GRASS GIS.

Fuller, D., C. Stevens (2009) Agriculture and the Development of Complex Societies: an archaeobotanical agenda. In: A. Fairbain and E. Weiss (eds.) From Foragers toFarmers: papers in honour of Gordon C. Hillman, pp.37-57. Oxford: Oxbow Books 
Fuller, D., H. Zhang (2007). A preliminary report of the survey archaeobotany of the upper Ying Valley (Henan Province). in: School of Archaeology and Museology in Peking University (SAMPU) and Henan Provincial Institute of Cultural Relics and Archaeology (HPICRA) (eds.), Archaeological Discovery and Research at the Wangchenggang Site in Dengfeng (2002-2005), pp. 916-958. Zhengzhou: Elephant Press.

Fuller, D., C. Stevens, M. McClatchie (in press). Routine Activities, Tertiary Refuse and Labor Organization: Social Inference from Everyday Archaeobotany. in: Madella, M., M. Savard (eds.), Ancient Plants and People: Contemporary Trends in Archaeobotany. Tucson: University of Arizona Press.

Harvey, E., D. Fuller (2005). Investigating crop processing using phytolith analysis: the example of rice and millets. Journal of Archaeological Science (32): 739-752.

Henan Provincial Bureau of Geology and Minerals (HPBGM) (1989). Henansheng quyu dizhi zhi (Henan Provincial Geology Record). in: zhonghua renmin gongheguo dizhi kuangchan bu dizhi zhuanbao (Geological Report of Department of Geology and Minerals for People's Republic of China). Vol.17. Beijing: Geology Press. (In Chinese).

Henan Provincal Institute of Cultural Relics (HPICR), Committee of Cultural Relics in Yuxian County (CCRYC) (1991). Henan yuxian yinghe liang'an kaogu diaocha yu shijue (Archaeological survey and excavation in Ying River Valley of Yuxian county, Henan Province). Kaogu 2: 97-104,106. (In Chinese).

Henan Provincial Institute of Cultural Relics and Archaeology (HPICRA), Department of Anthropology at the Missori State University (DAMSU) (1998). A preliminary report on the application of GPS and GIS in archaeological surveys in the upper Ying River Valley, Henan. Huaxia Kaogu 1: 1-16. (In Chinese).

Heyen, G. H. "Primitive navigation in the pacific" In Polynesian navigation: a symposium on Andrew Sharp's theory of accidental voyages, edited by Jack Golson. 3rd ed. Wellington: Polynesian Society, 1972.

Hillman, G. (1984a). Traditional husbandry and processing of archaic cereals in recent times: the operations, products and equipment which might feature in Sumerian texts. Bulletin On Sumerian Agriculture (Vol.1): 114-152.

Jin, G., F. Luan (2006). Haidai diqu longshan shidai daozuo nongye yanjiu de jinyu yu wenti. (Progress and problems of the research on the rice cultivation in Lonshan period of Haidai region). Nongye Kaogu 1, 52-61. (In Chinese).

Jin, G., Y. Fang, C. Wang (2007). Henan Dengfeng Wangchenggang yizhi turang 
yangpin de zhiguiti fenxi (Analysis of phytolith remains from Wangchenggang site in Dengfeng, Henang). Zhongyuan Wenwu 2: 93-100. (In Chinese).

Lee, G-A., S. Bestel (2007). Contextual analysis of plant remains at the Erlitou-Period Huizui site, Henan, China. Indo-Pacific Prehistory Association Bulletin 27, 49-60.

Lee, G-A., G. Crawford, L. Liu, X. Chen (2007). Plants and people from the Early Neolithic to Shang periods in North China. PNAS (Proceeding of the National Academy of Sciences of the United States America) 104 (3): 1087-1092.

Lee, Y.K. (2002). Building the chronology of early Chinese history. Asian Perspectives 41 (1): 15-42.

Li, Y. eds. (1998). Zhongguo zacao zhiwu zhi (Chinese Weed Flora). Beijing: China Agriculture Press. (In Chinese).

Liu, L., X. Chen (2003). State Formation in Early China. London: Duckworth.

Luoyang Archaeological Team, Institute of Archaeology, Chinese Academy of Science (LAT). (1961). 1959 nian yuxi liuxian diaocha jianbao (Preliminary report of archaeological surveys for six towns in west of Henan Province). Kaogu 1: 29-32. (In Chinese).

Mantel, N. (1967). The detection of disease clustering and a generalized regression approach. Cancer Research 27, 209-220.

Miller, J., Franklin, J. and R. Aspinall (2007). Incorporating spatial dependence in predictive vegetation models. Ecological Modelling 202: 225-242.

Qiao, Y. (2007). Development of complex societies in the Yiluo region: A GIS based population and agricultural area analysis. Indo-Pacific Prehistory Association Bulletin 27, 61-75.

School of Archaeology and Museology in Peking University (SAMPU) (2002). Luoyang Wangwan tianye kaog fajue baogao (Luoyang Wangwan: archaeological excavation report). Beijing: Peking University Press.

School of Archaeology and Museology in Peking University (SAMPU) and Henan Provincial Institute of Cultural Relics and Archaeology (HPICRA) (eds.), Archaeological Discovery and Research at the Wangchenggang Site in Dengfeng (2002-2005). Zhengzhou: Elephant Press.

Shennan, S. (1997). Quantifying Archaeology (Second Edition). Edinburgh: Edinburgh University Press. 
Speight, J.G. (1971). Log-normality of Slope Distributions, Zeitschrift für Geomorphologie 15: 291-311

Van der Veen, M., G. Jones (2006). A re-analysis of agricultural production and consumption: implications for understanding the British Iron Age. Vegetation History and Archaeobotany 15 (3): 217-228

Xu, X. (1959). 1959 nian xia yuxi diaocha Xiaxu de chubu baogao (Preliminary report of the surveys in the Ruins of Xia in 1959). Kaogu 11: 592-600. (In Chinese).

Wagstaff, M. and S. Auguston (1982). Traditional Land Use. in: C. Renfrew and M. Wagstaff (eds.), An Island Polity. The Archaeology of Exploitation in Melos, pp.106-133. Cambridge: Cambridge University Press.

Zahavi, Y. 1979 The 'UMOT' Project. Technical report, U.S. Department of Transportation and the German Ministry of Transport (Washington and Bonn).

Zhang, H. (2007). Yinghe zhongshangyou Dengfeng Yuzhou kaogu diaocha (Archaeological survey of upper and mid Ying River Valleys in Dengfeng and Yuxian Counties). in: School of Archaeology and Museology in Peking University (SAMPU) and Henan Provincial Institute of Cultural Relics and Archaeology (HPICRA) (eds.), Archaeological Discovery and Research at the Wangchenggang Site in Dengfeng (2002-2005), pp. 665-773. Zhengzhou: Elephant Press. (In Chinese).

Zhao, Z. (2005). Youguan nongye qiyuan he wenming qiyuan de zhiwu kaoguxue yanjiu. (Review of Archaeobotanical Researches on Origins of Agriculture and Civilization). Shehui Kexue Guanli Yu Pinglun 2005(2), 82-97. (In Chinese).

Zhao, Z. (2006). Guanyu xia shang zhou wenming xingcheng shiqi nongye jingji tedian de yixie sikao. (On the distinctive features of agricultural economy during the formation of Xia Shang Zhou civilization). Huaxia Kaogu 1, 75-81. (In Chinese).

Zohary, D and Hopf, M.(2000). Domestication of plants in the Old World : The origin and spread of cultivated plants in West Asia, Europe and the Nile Valley, 3rd ed. Oxford: Oxford University Press, 57 - 58. 


\section{Tables}

$\begin{array}{cccccc}\text { Site Name } & \text { Full Name } & \text { Period } & \begin{array}{c}\text { No. of } \\ \text { Samples }\end{array} & \begin{array}{c}\text { No. of } \\ \text { Species }\end{array} & \text { No. of Seeds } \\ 1 & \text { Wangchenggang } & \text { Longshan } & 72 & 12 & 2601 \\ 2 & \text { Chengyao } & \text { Longshan } & 2 & 14 & 2110 \\ 3 & \text { Xifandian } & \text { Erlitou } & 3 & 26 & 287 \\ 4 & \text { Youfangtou } & \text { Longshan } & 1 & 17 & 681 \\ 5 & \text { Yuancun } & \text { Yangshao/Longshan } & 1 & 18 & 181 \\ 6 & \text { Yangcun } & \text { Yangshao/Longshan } & 2 & 21 & 232 \\ 7 & \text { Shidao } & \text { Erlitou } & 3 & 22 & 756 \\ 8 & \text { Shiyangguan } & \text { Yangshao/Longshan } & 1 & 33 & 329 \\ 10 & \text { Yuanqiao } & \text { Yangshao/Erlitou } & 2 & 3323\end{array}$

Table 1. Archaeobotanical data for the upper Ying valley survey by site. Note that the Wangchenggang values are summaries from the published excavation data (SAMPU \& HPICRA 2007). 


\begin{tabular}{|c|c|c|c|c|c|c|}
\hline Site Name & Rice/Millet & Setaria/Panicum & $\begin{array}{c}\% \text { Wetland } \\
\text { Weed }\end{array}$ & $\begin{array}{c}\text { \% Dryland } \\
\text { Weed }\end{array}$ & $\%$ Soybeans & $\begin{array}{l}\% \text { Wild } \\
\text { fruits }\end{array}$ \\
\hline Wangchenggang & 0.0074 & 1.6575 & 0.0012 & 0.0104 & 0.0927 & 0 \\
\hline Chengyao & 0.7338 & 29 & 0.0055 & 0.2680 & 0 & 0 \\
\hline Xifandian & 0.0515 & 16.5 & 0.0592 & 0.4007 & 0.0035 & 0 \\
\hline Youfangtou & 0.036 & 6.1081 & 0.0059 & 0.3642 & 0.0191 & 0.0029 \\
\hline Yuancun & 0.0526 & 14.5556 & 0 & 0.2983 & 0.0055 & 0 \\
\hline Yangcun & 0 & 3.4737 & 0.0086 & 0.1293 & 0 & 0.0086 \\
\hline Shidao & 0.0416 & 18.1395 & 0.0066 & 0.0146 & 0.0067 & 0.004 \\
\hline Shiyangguan & 0.0748 & 37.5 & 0.003 & 0.0821 & 0 & 0.0152 \\
\hline Yuanqiao & 0.0018 & 28.3 & 0.0045 & 0.1177 & 0.2832 & 0.0849 \\
\hline
\end{tabular}

Table 2. Six measures of arable ecology based on archaeobotanical data from the sampled upper Ying valley sites. 
Initial Eigenvalues

$\begin{array}{cccccccccc}\text { Component } & \text { Total } & \begin{array}{c}\text { \% of } \\ \text { Variance }\end{array} & \begin{array}{c}\text { Cumulative } \\ \text { \% }\end{array} & \text { Total } & \begin{array}{c}\text { \% of } \\ \text { Variance }\end{array} & \begin{array}{c}\text { Cumulative } \\ \%\end{array} & \text { Total } & \begin{array}{c}\text { \% of } \\ \text { Variance }\end{array} & \begin{array}{c}\text { Cumulative } \\ \%\end{array} \\ 1 & 2.359 & 39.313 & 39.313 & 2.359 & 39.313 & 39.313 & 2.100 & 34.992 & 34.992 \\ 2 & 1.451 & 24.178 & 63.490 & 1.451 & 24.178 & 63.490 & 1.538 & 25.632 & 60.624 \\ 3 & 1.269 & 21.154 & 84.645 & 1.269 & 21.154 & 84.645 & 1.441 & 24.021 & 84.645 \\ 4 & .563 & 9.386 & 94.031 & & & & & & \\ 5 & .318 & 5.301 & 99.331 & & & & & & \end{array}$

\begin{tabular}{cc}
\multicolumn{2}{c}{ Communalities } \\
Initial & Extraction \\
1.000 & .765 \\
1.000 & .819 \\
1.000 & .831 \\
1.000 & .799 \\
1.000 & .894 \\
1.000 & .970
\end{tabular}

\begin{tabular}{ccc}
\multicolumn{3}{c}{ Rotated Component } \\
AEF1 & AEF2 & AEF3 \\
-.220 & .834 & .144 \\
$-2.036 \mathrm{E}-02$ & .898 & -.113 \\
-.311 & $2.347 \mathrm{E}-02$ & .857 \\
.372 & $-5.503 \mathrm{E}-03$ & .813 \\
.929 & -.155 & $-7.859 \mathrm{E}-02$ \\
.975 & -.108 & $8.544 \mathrm{E}-02$
\end{tabular}

Table 3. Results from Principal Component Analysis of six arable ecology variables. 


$\begin{array}{ccccc}\text { Site Name } & \begin{array}{c}\text { Mean of Maximum } \\ \text { Weed Height }\end{array} & \begin{array}{c}\text { Mean of Minimum } \\ \text { Weed Height }\end{array} & \text { Grains/Weeds } & \begin{array}{c}\text { Hulled \& Immature/ } \\ \text { Unhulled \& Mature }\end{array} \\ \text { Chengyao } & 89.5833 & 47.05 & 2.190909 & 0.66207 \\ \text { Xifandian } & 97.1831 & 41.6197 & 1.554348 & 0.31818 \\ \text { Youfangtou } & 107.9699 & 49.5489 & 1.608392 & 0.47345 \\ \text { Yuancun } & 81.7391 & 46.3044 & 2.545454 & 0.19084 \\ \text { Yangcun } & 95.7143 & 46.1539 & 7.478261 & 0.22727 \\ \text { Shidao } & 75.7143 & 28.3333 & 9.102273 & 0.30114 \\ \text { Shiyangguan } & 59.6667 & 18.6 & 4.893617 & 0.20444 \\ \text { Yuanqiao } & 104.9495 & 46.404 & 5.026471 & 0.23911\end{array}$

Table 4. Four measures of crop processing strategy based on archaeobotanical data from the sampled upper Ying valley sites. 
Initial Eigenvalues

Component

$$
\begin{array}{ccc}
\text { Total } & \% \text { of } & \text { Cumulative } \\
& \text { Variance } & \%
\end{array}
$$

4.086

2.345

1.410

1.125

0.677

0.239

0.114

40.858

23.452

14.102

11.252

6.772

2.387

1.144

3.410E-03 3.410E-02

$2.123 \mathrm{E}-16 \quad 2.123 \mathrm{E}-15$

$-6.018 \mathrm{E}-16$
Extraction Sums of Squared Loadings

Total \% of Cumulative Variance 40.858 40.858 64.309 78.412 89.663 96.435 98.822

99.966

100.000

100.000

\begin{tabular}{|c|c|c|c|c|c|c|}
\hline \multirow{2}{*}{ variables } & \multicolumn{2}{|c|}{ Communalities } & \multicolumn{4}{|c|}{ Rotated Component } \\
\hline & Initial & Extraction & $N E F 1$ & $N E F 2$ & $N E F 3$ & NEF4 \\
\hline slope & 1.000 & 0.983 & -0.419 & 0.787 & -0.144 & -0.409 \\
\hline exposure to easterly wind & 1.000 & 0.598 & -0.742 & -0.138 & -0.165 & $2.786 \mathrm{E}-02$ \\
\hline exposure to northwesterly wind & 1.000 & 0.977 & $-8.248 \mathrm{E}-02$ & $3.352 \mathrm{E}-02$ & 0.130 & 0.976 \\
\hline flow accumulation & 1.000 & 0.904 & 0.785 & -0.530 & $-7.495 \mathrm{E}-02$ & $2.689 \mathrm{E}-02$ \\
\hline annual rainfall & 1.000 & 0.839 & 0.426 & 0.107 & 0.762 & 0.258 \\
\hline river terrace & 1.000 & 0.796 & 0.875 & -0.132 & 0.112 & $2.547 \mathrm{E}-02$ \\
\hline cinnamon soil & 1.000 & 0.962 & 0.196 & 0.934 & $9.329 \mathrm{E}-02$ & 0.206 \\
\hline chao soil & 1.000 & 0.992 & 0.691 & -0.716 & $-2.907 \mathrm{E}-02$ & $3.712 \mathrm{E}-03$ \\
\hline purplish soil & 1.000 & 0.957 & -0.428 & $4.312 \mathrm{E}-02$ & 0.844 & -0.242 \\
\hline skeletal soil & 1.000 & 0.957 & -0.365 & 0.103 & -0.824 & -0.368 \\
\hline
\end{tabular}

100.000

Table 5. Results from Principal Component Analysis of the natural environment variables. 


\begin{tabular}{llllll} 
Yangshao & $r^{2}$ with & \multicolumn{4}{l}{ Natural Environmental Diversity Factor } \\
Period & significance & NEF1 & NEF2 & NEF3 & NEF4 \\
Arable Ecology Factor & AEF1 & $\mathbf{0 . 9 6 7} 0.017$ & $0.562_{0.246}$ & $\mathbf{0 . 8 4 9} 0.079$ & $0.239_{0.511}$ \\
& AEF2 & $0.000_{0.981}$ & $0.516_{0.282}$ & $0.032_{0.821}$ & $\mathbf{0 . 7 5 4}_{\mathbf{0 . 1 3 2}}$ \\
& AEF3 & $0.146_{0.618}$ & $0.050_{0776}$ & $0.337_{0.420}$ & $0.269_{0.481}$ \\
Longshan-Erlitou & $r^{2}$ with & Natural Environmental Diversity Factor & \\
Period & significance & NEF1 & NEF2 & NEF3 & NEF4 \\
Arable Ecology Factor & AEF1 & $0.023_{0.807}$ & $0.017_{0.836}$ & $0.021_{0.818}$ & $0.030_{0.782}$ \\
& AEF2 & $0.110_{0.586}$ & $0.051_{0.714}$ & $0.056_{0.701}$ & $\mathbf{0 . 5 8 6} 0.132$ \\
& AEF3 & $0.011_{0.868}$ & $0.190_{0.464}$ & $0.002_{0.948}$ & $0.356_{0.288}$
\end{tabular}

Table 6. Results from global linear regressions that consider the relationship between arable ecology and natural environmental diversity for a) the Yangshao period and b) the Longshan to Erlitou period (boldface and italicised numbers are those with greater statistical significance and discussed in the text). 


\begin{tabular}{|c|c|c|c|c|c|c|c|c|c|}
\hline & $\begin{array}{l}\text { Connec- } \\
\text { tivity }\end{array}$ & $\begin{array}{l}\text { Access- } \\
\text { ibility }\end{array}$ & Distance & $\begin{array}{l}\text { Adjacen- } \\
\text { cy }\end{array}$ & $\begin{array}{l}\text { Chrono- } \\
\text { Logy }\end{array}$ & $N E F 1$ & $N E F 2$ & $N E F 3$ & $N E F 4$ \\
\hline Connectivity & 1 & 0.334 & 0.432 & 0.437 & 0.119 & -0.145 & -0.405 & -0.248 & 0.202 \\
\hline Accessibility & & 1 & 0.418 & 0.489 & 0.091 & 0.027 & -0.320 & 0.794 & 0.299 \\
\hline Distance & & & 1 & 0.729 & -0.064 & -0.275 & 0.069 & 0.466 & 0.365 \\
\hline Adjacency & & & & 1 & 0.139 & -0.263 & -0.252 & 0.483 & 0.370 \\
\hline Chronology & & & & & 1 & -0.129 & -0.110 & 0.189 & -0.033 \\
\hline$N E F 1$ & & & & & & 1 & 0.327 & -0.057 & 0.055 \\
\hline$N E F 2$ & & & & & & & 1 & -0.377 & -0.113 \\
\hline$N E F 3$ & & & & & & & & 1 & 0.290 \\
\hline NEF4 & & & & & & & & & 1 \\
\hline
\end{tabular}

Table 7. Results from a Mantel matrix test that considers interdependence amongst chronological and environmental factors (boldface and italicised numbers are significant at $\mathrm{p}<0.05$ or better). 


\begin{tabular}{|c|c|c|c|c|c|c|c|c|c|}
\hline & $\begin{array}{l}\text { Connec- } \\
\text { tivity }\end{array}$ & $\begin{array}{l}\text { Accessi- } \\
\text { bility }\end{array}$ & Distance & $\begin{array}{l}\text { Adjacen- } \\
\text { cy }\end{array}$ & $\begin{array}{l}\text { Chrono- } \\
\operatorname{logy}\end{array}$ & $N E F 1$ & $N E F 2$ & $N E F 3$ & NEF4 \\
\hline \multirow{2}{*}{$\begin{array}{l}\text { Grain to } \\
\text { weed }\end{array}$} & 0.171 & 0.629 & 0.341 & 0.269 & 0.134 & -0.206 & -0.148 & 0.524 & 0.128 \\
\hline & & 0.412 & & & & & & 0.051 & \\
\hline \multirow{2}{*}{$\begin{array}{l}\text { Hulled\&i } \\
\text { mmature } \\
\text { grain }\end{array}$} & 0.063 & 0.117 & -0.267 & 0.095 & 0.566 & -0.137 & -0.112 & -0.041 & -0.277 \\
\hline & & 0.247 & & & & & & -0.222 & \\
\hline \multirow{4}{*}{$\begin{array}{l}\text { Max } \\
\text { weed } \\
\text { height } \\
\text { Mix weed } \\
\text { height }\end{array}$} & 0.144 & -0.082 & 0.428 & 0.412 & -0.233 & -0.129 & 0.209 & -0.115 & 0.179 \\
\hline & & 0.015 & & & & & & -0.082 & \\
\hline & 0.194 & 0.177 & 0.675 & 0.644 & -0.050 & -0.239 & -0.076 & 0.157 & 0.390 \\
\hline & & 0.087 & & & & & & 0.027 & \\
\hline
\end{tabular}

Table 8. Results from a Mantel matrix test that considers the environmental factors correlated with particular farming activities (boldface and italicised numbers are significant at $\mathrm{p}<0.05)$. 


\section{Figure Captions}

Figure 1. Location maps of: a) the Ying river valley in the central plain of China and b) archaeological sites in the upper Ying valley.

Figure 2. Primary environmental datasets: a) a 30m digital elevation model derived from ASTER imagery (with extracted stream network shown), b) geology enhanced via comparison with ASTER SWIR (the latter not shown), c) total annual precipitation, d) soil types.

Figure 3. Anisotropic cost surfaces used to suggest site catchments: a) an example of an r.walk cost surface from the Longshan site of Wangchenggang with the one hour isoline shown in black; b) an example for the Longshan phase of suggested sites catchments as mapped through a combination of the limit of 1-hour travel and allocation to the nearest site.

Figure 4. Suggested social networks in the upper Ying valley for sites from: a) the Yangshao phase, b) the Longshan phase and c) the Erlitou phase.

Figure 5. Prehistoric stone tools for harvesting from the Ying valley (drawings by Li Yangsong (SAMPU 2002:34)). 


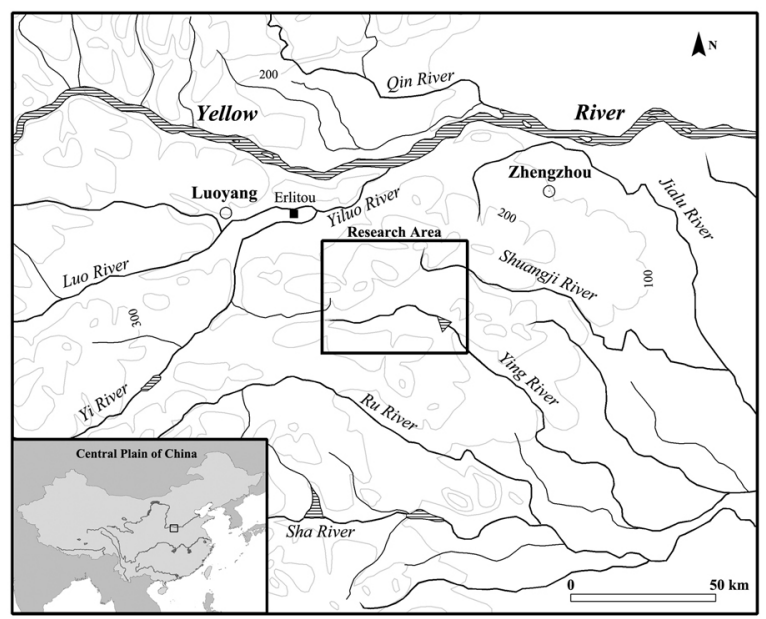




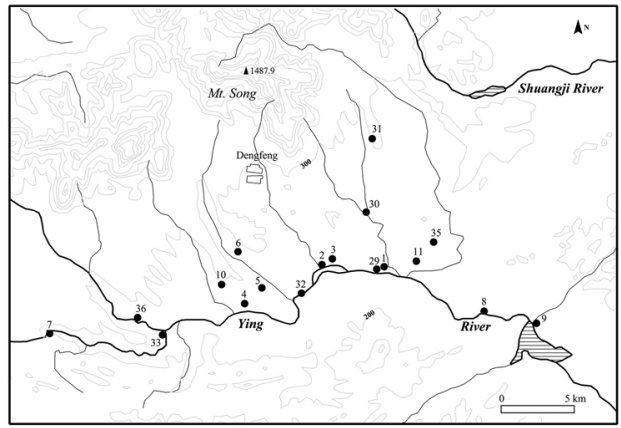




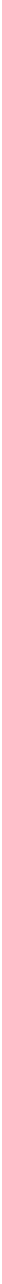




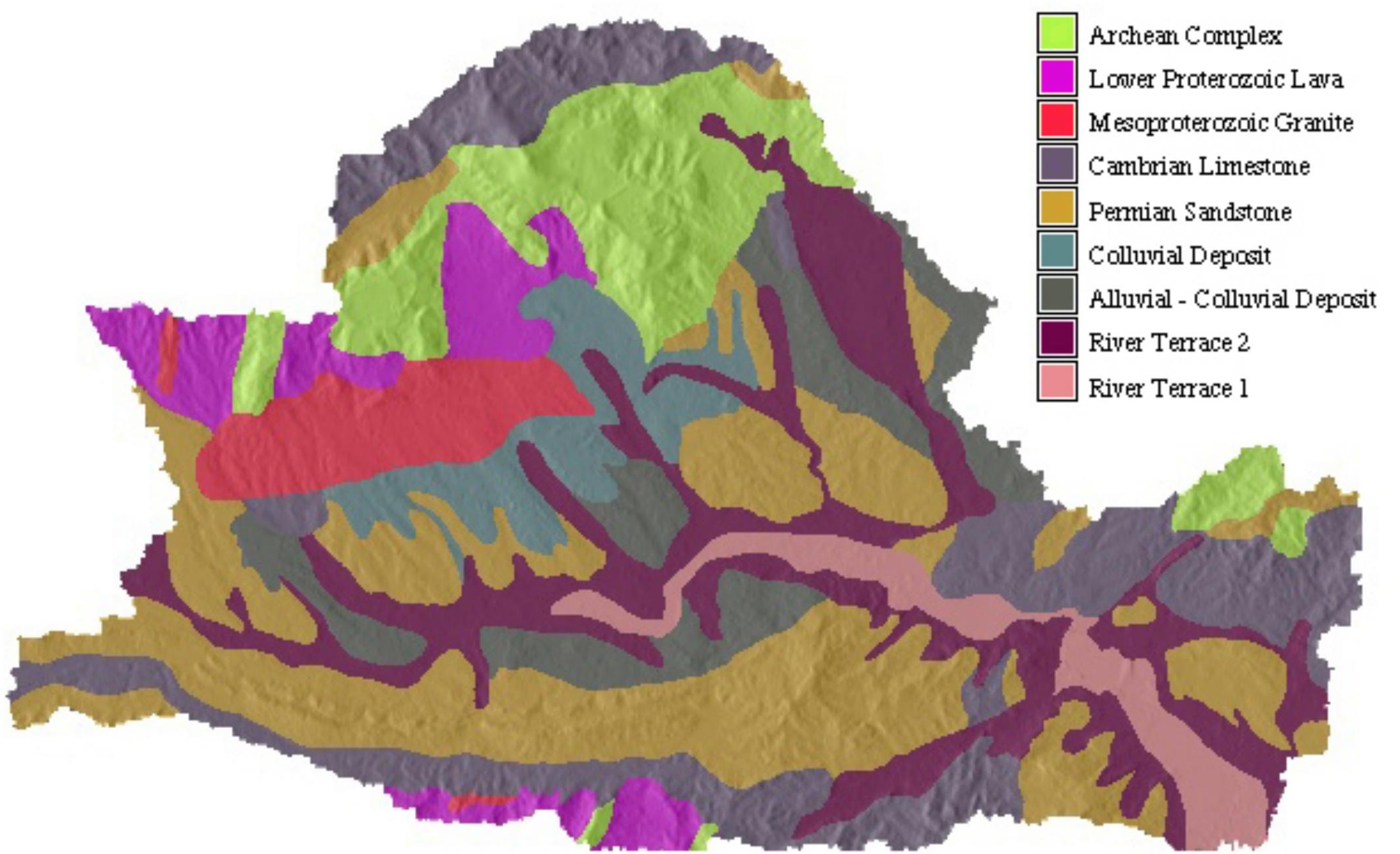




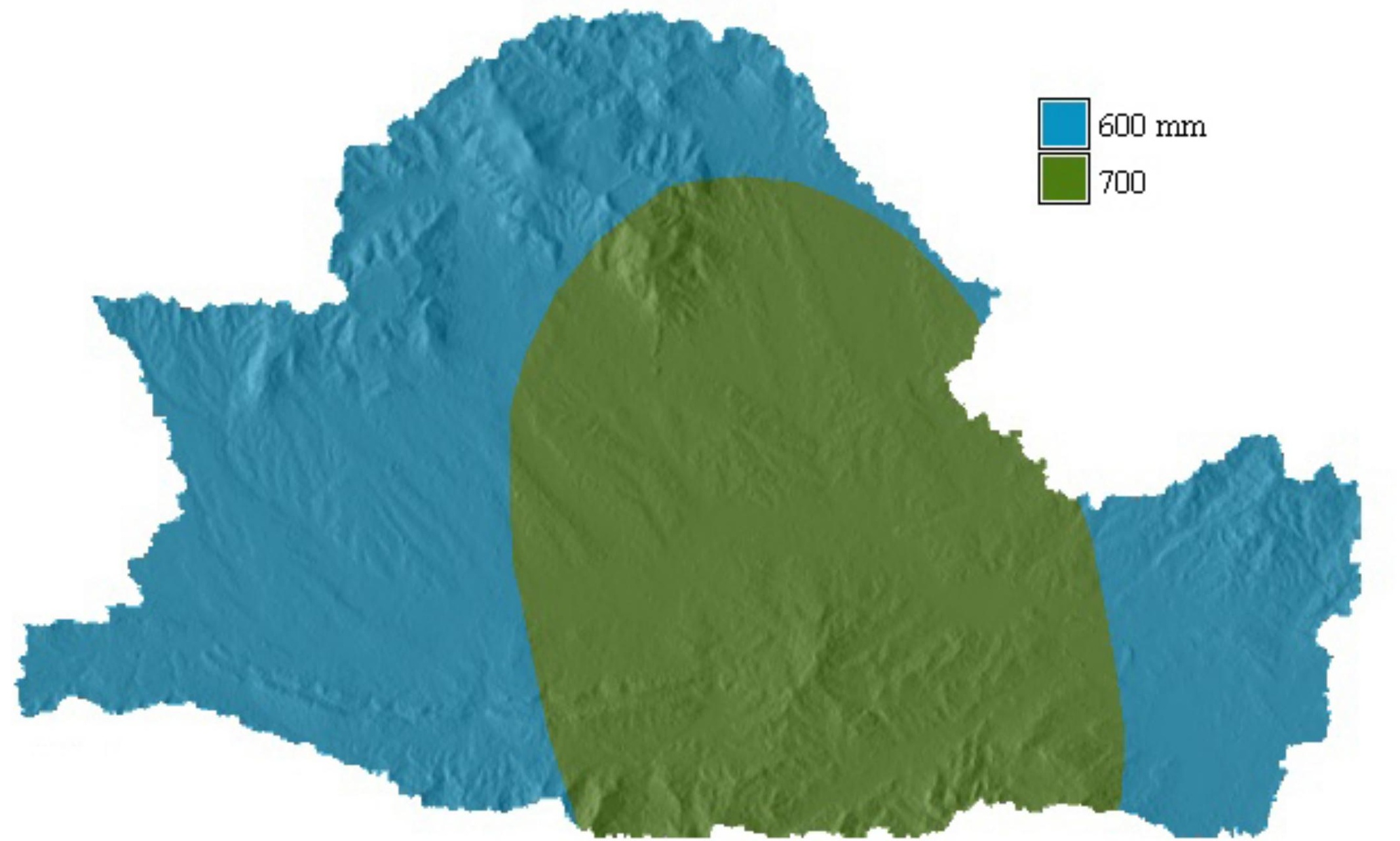




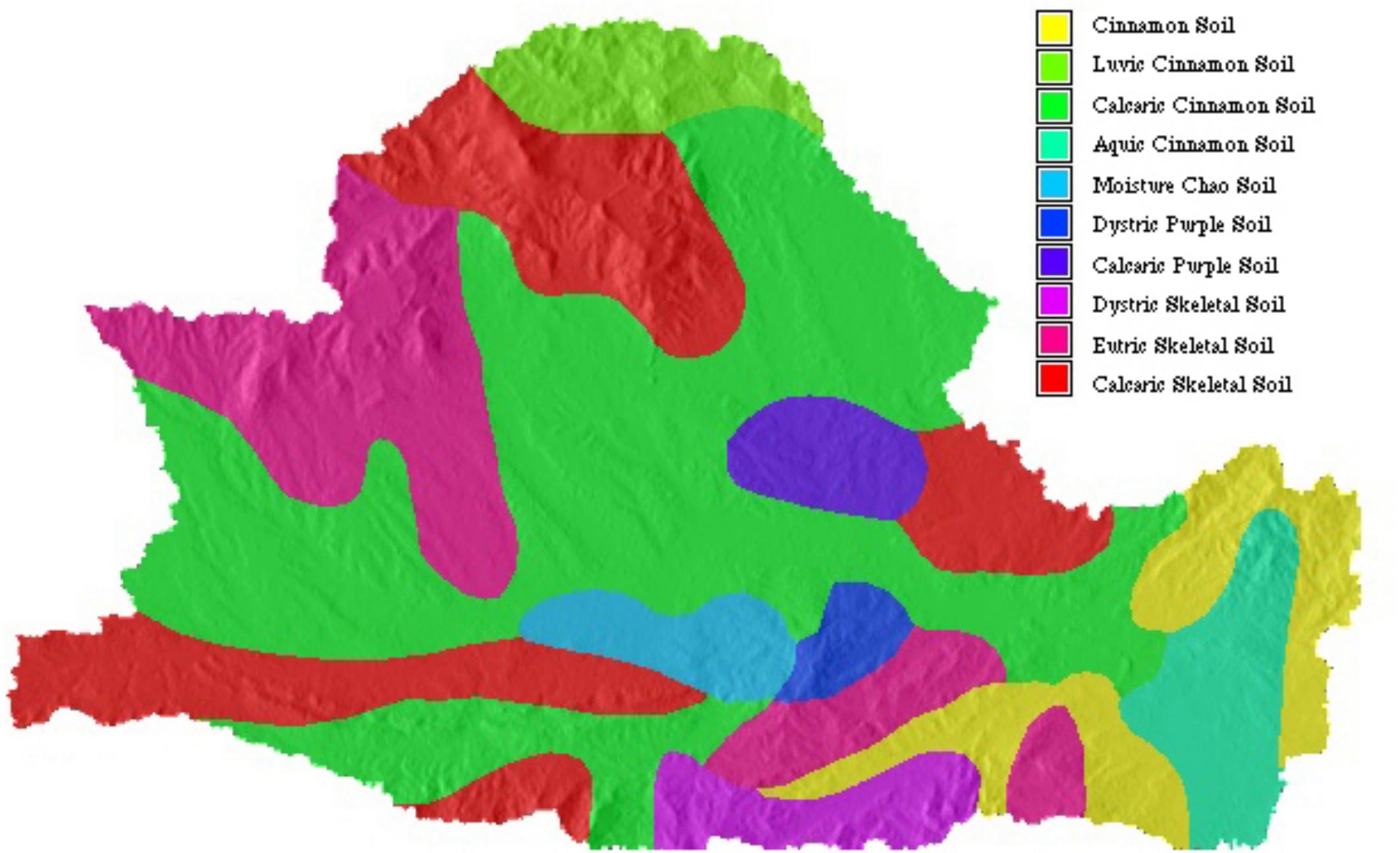




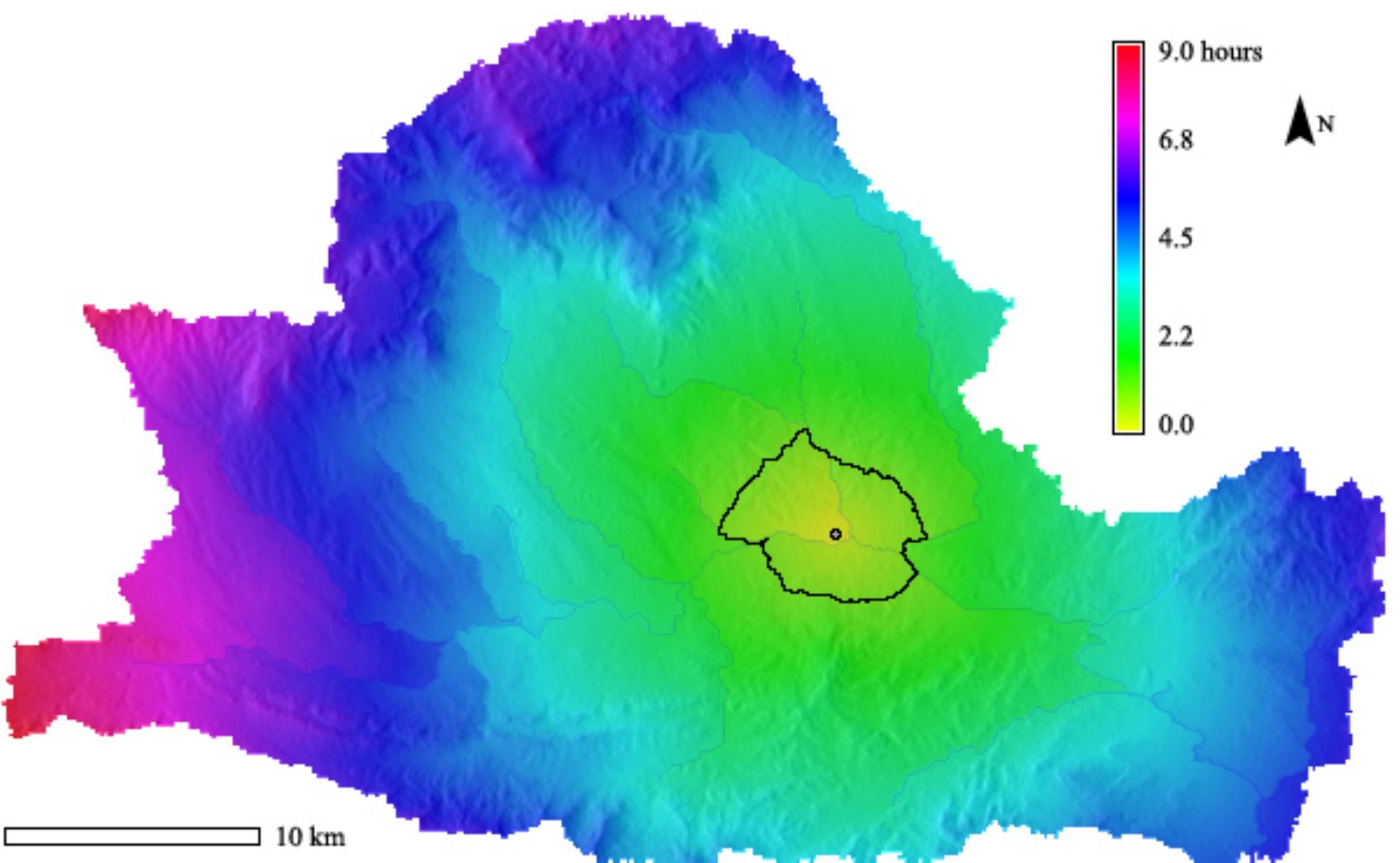




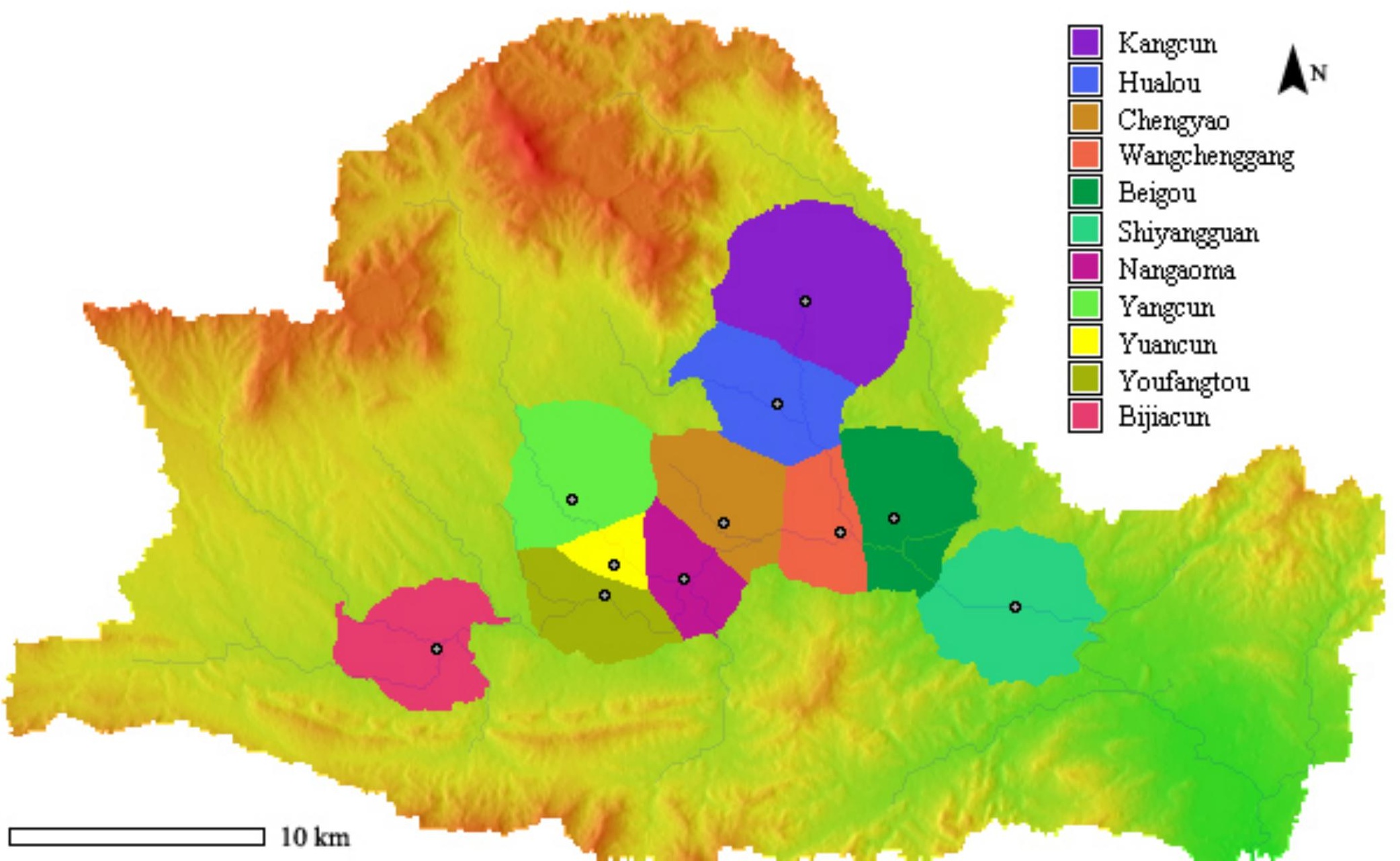




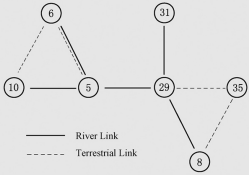




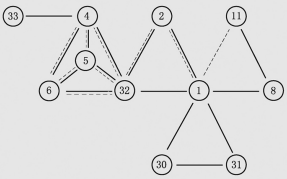




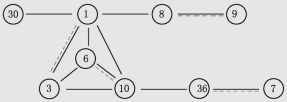


